* Mestre em Direito Empresarial pela Faculdade Milton Campos, com bolsa da Coordenação de Aperfeiçoamento de Pessoal de Nível Superior - CAPES. Pós-graduando lato sensu em Direito Tributário pelo IBET. Graduado em Direito pelo Centro Universitário de João Pessoa. Professor da Pós-Graduação em Direito Tributário do Instituto de Ensino Superior da Paraíba (IESP) e Professor da Pós-Graduação em Direito Administrativo das Faculdades Integradas da Paraíba - FIP. Advogado e Consultor jurídico.

E-mail: eduardosfrade@hotmail. com

**Doutor em Direito pela Universidade Federal de Minas Gerais - UFMG. Mestre em Direito Universidade Federal de Minas Gerais - UFMG. Professor da Universidade Federal de Minas Gerais (UFMG), da Escola Superior Dom Helder Câmara ESDHC e da Faculdade Milton Campos - FDMC. Advogado e Consultor jurídico.

E-mail: marcio.luiz@uol.com.br

\section{Cooperativismo de Crédito: uma Alternativa de DeSENVOLVIMENTo SOCIOECONôMico}

\author{
Credit Cooperativism: an Alternative to \\ SOCIOECONOMIC DEVELOPMENT
}

\section{Eduardo Silveira Frade* Márcio Luís de Oliveira**}

Como citar: FRADE, Eduardo Silveira; OLIVEIRA, Márcio Luís. Cooperativismo de crédito: uma alternativa de desenvolvimento socioeconômico. Revista do Direito Público, Londrina, v. 13, n. 3, p. 153-174, dez. 2018. DOI: 10.5433/24157108104-1.2018v13n3 p 153. ISSN: 1980-511X.

Resumo: $O$ cooperativismo de crédito apresenta valores e características que o tornam vantajoso como modelo de concessão de crédito e, por isso, benéfico para o desenvolvimento socioeconômico. O artigo busca demonstrar e justificar esses valores e características de modo a tornar o cooperativismo de crédito objeto de políticas públicas adequadas para estimulálo e viabilizá-lo de modo eficiente, cuja análise perpassa o reconhecimento de sua importância como instrumento de desenvolvimento socioeconômico. Na elaboração do trabalho adota-se a metodologia analítico-dogmática, com auxílio de textos históricos, doutrina jurídica e relatórios proferidos por entidades estatais cuja competência se reflete sobre a fiscalização e promoção do cooperativismo de crédito, bem como de consulta à legislação.

Palavras-chave: Cooperativismo de crédito; Política pública; Sociedade cooperativa; Desenvolvimento socioeconômico.

\begin{abstract}
Credit cooperativism presents valuable traits that makes it an advantageous model for granting credit and is, therefore, beneficial to sustainable socioeconomic development. This paper demonstrates and justifies its usefulness to society in order to make credit cooperativism a central object of public policies. Consequentially, the State should stimulate and enable it to work efficiently, as society needs to recognize the importance
\end{abstract}


of credit cooperativism in the socioeconomic development of Brazil. This study utilized an analytical-dogmatic model of research, with the aid of historical texts, legal doctrine and data from State authorities - whose competence is to oversse and promote credit cooperativism, as well as offering public access to related legal regulations and norms.

Keywords: Credit cooperativism; Public policies; Cooperative society; Socioeconomic development. 


\section{INTRODUÇÃO}

A Constituição da República Federativa do Brasil, em seu artigo 174, § 2 ${ }^{\circ}$, estimula o cooperativismo e outras formas de associativismo. Desta feita, adota um modelo atualizado de intervenção na economia e opta pelo cooperativismo como uma das alternativas para se alcançar o desenvolvimento nacional, pré-determinado no seu artigo $3^{\circ}$, inciso II. (BRASIL, 1988).

Nesse cenário, a cooperativa de crédito é uma das modalidades de cooperativismo que tem crescido substancialmente no Brasil. Sob este prisma, almeja-se responder o seguinte questionamento: quais são os valores e as características do cooperativismo de crédito que o habilitam a ser considerado como alternativa economicamente viável para a implementação de políticas públicas de equidade socioeconômica?

Para se responder ao tema-problema, parte-se da hipótese de que o cooperativismo de crédito apresenta certos valores e características que o tornam vantajoso como modelo de concessão de crédito e, por isso, benéfico para o desenvolvimento nacional. Assim, o marco teórico da pesquisa é de substrato científico-dogmático, pois se assenta no marco jurídico-constitucional de estímulo ao cooperativismo (artigo 174, $\S 2^{\circ}$, da Constituição da República Federativa do Brasil) e nas propriedades inerentes ao cooperativismo de crédito.

Por conseguinte, este trabalho tem como objetivo geral apresentar os valores e as principais características do cooperativismo de crédito como modalidade econômica, bem como refletir sobre os fundamentos que deveriam torná-lo objeto de políticas públicas permanentes por parte do Estado, de modo a se desvelar como instrumento eficaz de estímulo ao desenvolvimento previsto na Constituição. Nesse sentido, serão identificados os benefícios que o cooperativismo de crédito pode trazer para gerar produção e equidade socioeconômica.

Na elaboração do trabalho adota-se a metodologia analítico-dogmática, com auxílio de textos históricos, doutrina jurídica e consulta à legislação.

A temática deste artigo é relevante no estudo do desenvolvimento. A necessidade de compreensão dos valores e das características do cooperativismo de crédito se faz justificável para que políticas públicas mais adequadas ao seu fomento sejam implementadas em todos os níveis da Federação. O conhecimento de suas peculiaridades em relação a outras formas de concessão de recursos financeiros permite uma melhor avaliação acerca da importância do modelo econômico cooperativista de crédito como alternativa para o desenvolvimento nacional com maior justiça social e menor desigualdade regional e local.

Para tanto, inicia-se o estudo com o regramento constitucional do cooperativismo. No segundo tópico, faz-se um breve relato histórico do cooperativismo, com ênfase no cooperativismo de crédito, demonstrado como este modelo econômico atingiu expressão em todo o mundo. Nos itens seguintes são abordados o conceito e as funções do cooperativismo de crédito e os valores 
que o fundamentam. Relata-se, ainda, acerca das características que diferenciam o cooperativismo de crédito dos bancos comerciais para se comprovar as suas vantagens. Por fim, discorre-se sobre o crescimento da adoção do cooperativismo de crédito no Brasil.

\section{A ORIGEM DO COOPERATIVISMO DE CRÉDITO}

O cooperativismo, como modalidade de associativismo, está correlacionado à dinâmica socioeconômica de desenvolvimento no Estado Liberal, notadamente pelas implicações sociais provenientes da Revolução Industrial do século XIX.

O liberalismo econômico tem por alicerce a mais-valia, compreendida como vetor de acumulação, ou seja, "um diferencial entre o valor agregado pelo trabalho ao produto final e o valor efetivamente apropriado pelo trabalho como remuneração do fator." (COURI, 2001, p. 25). Dessa compreensão de mais-valia decorrem consequências sociais, detectadas não somente pelos socialistas, cuja inspiração subsiste nos escritos de Karl Marx, mas como resultado empírico que promoveu a readaptação do modelo de produção capitalista, sobretudo após a crise de 1929.

Apesar das críticas à concepção da mais-valia nos moldes definidos por Karl Marx, (por não considerar os preços relativos e, consequentemente, a concorrência entre os empresários como fator de redução de lucro e de preço para o consumidor, bem como sua internalização pelo risco da atividade econômica), certo é que a partir dela se atentou sobre as diferenças socioeconômicas entre os detentores do capital e a classe proletária. Desta forma, é imperioso concluir que, como consequência da mais valia, acentua-se o abismo entre classes, dado às diferenças econômicas pela concentração e transmissão intraclasse da renda e de poder aquisitivo entre elas. Mas, para Oliveira (2016, p. 204), "o associativismo crescente dos trabalhadores, os movimentos feministas e o avanço revolucionário das ideias socialistas repercutiram profundamente na mentalidade e nas práticas liberais desvirtuadas na passagem do século XIX para o XX.”

Naquele ambiente socioeconômico, e em decorrência da baixa capacidade de consumo da classe proletária, começaram a surgir, na Inglaterra, em meados do século XIX, movimentos de associativismo entre os trabalhadores com o objetivo de adquirir produtos industriais, inclusive para expandir o seu poder de barganha perante os detentores do capital e de modo que houvesse a redução do valor dos produtos por eles negociados. Foi nesse contexto que, em 1844, na cidade britânica de Rochdale, foi constituída a primeira cooperativa, sendo formada pela agregação de esforços destinados ao consumo de bens industriais, formada por 28 tecelões, dentre os quais somente uma mulher, como observa João Paulo Koslovski (2001, p. 21).

Em que pese a primeira cooperativa ter surgido em 1844, o associativismo manufatureiro tem origens mais remotas, pois desde as corporações de ofício, surgidas entre a Alta e a Baixa Idade Médica, verifica-se a reunião de indivíduos com o objetivo comum de produção de bens. Todavia, pode-se afirmar que, naquela época, não havia ainda o cooperativismo, dada a ausência 
de seus elementos jurídico-econômicos, existindo apenas a reunião de pessoas sem animus de constituírem entre si uma sociedade empresarial de produção.

A cooperativa de Rochdale, denominada de Society of Equitable Pioneers inaugurou, portanto, uma nova forma de associativismo, na medida em que, a partir dela, se verificou a intenção de constituição de uma sociedade, pois seus fundadores cuidaram de dispor de seu próprio capital particular para formar um capital social, inicialmente destinado à aquisição de um armazém para o estoque de mercadorias a serem utilizadas por todos os sócios.

A cooperativa de Rochdale, ademais de fundar um armazém destinado ao favorecimento de associados,

[...] almejava também a construção de casas para fornecer alojamento a preços de custo; a formação de um capital para a emancipação do proletariado por meio da economia conseguida pela compra em comum de gêneros alimentícios; a criação de estabelecimentos industriais e agrícolas para, além de produzir para promover as necessidades da classe operária, assegurar trabalho aos operários desempregados ou com salários baixos; a construção de estabelecimentos de temperança a fim de combater o alcoolismo; a criação de pequenos núcleos nos quais a produção e a repartição fossem organizadas; a multiplicação destes núcleos por meio do exemplo e propaganda (ROSSI, 2011, p. 41).

Destarte, a cooperativa de Rochdale ergueu as premissas sobre as quais seriam projetadas as demais cooperativas que a seguiram, fossem destinadas a consumo ou não. O cooperativismo, portanto, propunha aos associados a possibilidade de transcenderem da classe proletária, conseguindo, assim, melhores condições de vida tanto para si como para os demais colegas de empreitada, pois, como assenta Prado (2011, p. 40) tinha a ajuda mútua como ideia básica, unindo forças contra um inimigo comum, qual seja a exploração do trabalho humano pelos detentores do capital.

Os números, per si, exprimem a importância do cooperativismo. Como demonstra Singer (2002, p. 130), em 1881, o número de associados chegou a 547 mil e, em 1900, atingiu 1,7 milhão, o que sem dúvidas, serviu de estímulo para que o movimento cooperativo tomasse força, independentemente da finalidade originária de cada cooperativa.

A constituição de cooperativa com a finalidade de oferta de crédito para os associados não tardou a aparecer. Como se depreende de Pinheiro (2008, p. 23), a primeira cooperativa de crédito foi fundada na Alemanha, em 1864, por Friedrich Wilhelm Raiffeisen, denominada de Heddesdorfer Darlehnskassenveirein (Associação de Caixas de Empréstimo de Haddesdorf). Essa cooperativa foi especialmente destinada ao apoio creditício para a população rural daquela região, que se via restringida a empréstimos com altas taxas de juros, cobrados por agentes industriais locais, detentores de capital, o que lhes dificultava a produção agropecuária

Sobre as características das cooperativas rurais alemãs, destaca-se a "responsabilidade ilimitada e solidária dos associados, a singularidade de votos dos sócios, independentemente do número de quotas-parte, a área de atuação restrita, a ausência de capital social e a não-distribuição 
de sobras, excedentes ou dividendos." (PINHEIRO, 2008, p. 23). Outrossim, cumpre destacar, conforme aponta Oliveira (2005, p. 32), que, em 1888, já havia cerca de 400 sociedades de crédito constituídas nos moldes de Raiffeisen, o que demonstra a repercussão e a popularidade que esse tipo de associativismo rural alcançou na Alemanha.

As cooperativas de crédito urbanas também tiveram origem na Alemanha, desta vez na cidade de Delitzsch, tendo como precursor Hermman Schulze, passando a ser conhecidas como tipo "Schulze-Delitzsch". Em sua primeira fase, foram criadas como cooperativas de produção para atender artesãos locais e, numa segunda etapa, fomentaram o financiamento destes mesmos artesãos, razão pela qual assumiram a natureza creditícia. A diferença fundamental deste modelo em relação ao proposto por Raiffeisen é que há, neste, a possibilidade de retorno de sobras líquidas proporcionalmente ao capital investido, bem como não há área de atuação restrita, além de haver remuneração dos dirigentes, como destaca Pinheiro (2008, p. 23). Esse modelo cooperativo também encontrou ampla difusão na Alemanha. Tanto que Moreno (1999, p. 16) afirma que, em 1861, já havia 340 cooperativas do tipo "Schulze-Delitzsch", sob a denominação de Bancos Populares.

A confluência das ideias de Schulze e Raiffeisen rapidamente se espalharam por toda a Europa Ocidental. Em 1865, na cidade italiana de Milão, Luigi Luzzatti organizou a primeira cooperativa de crédito do país, inaugurando um modelo que herdaria seu sobrenome, o tipo Luzzatti, a princípio destinada à concessão de crédito rural. Segundo Pinheiro (2008, p. 23) aquela forma de cooperativismo tinha, como algumas de suas características, a não exigibilidade de vínculo específico dentre os associados - à exceção da limitação geográfica previamente definida -, quotas de capital de pequeno valor, a não necessidade de garantias reais para a concessão de pequenos empréstimos, bem como a não remuneração dos dirigentes e a responsabilidade limitada dos associados ao capital por eles subscritos, o que serviria de inspiração para o cooperativismo de crédito brasileiro, sobretudo entre as décadas de 1940 e 1960.

O cooperativismo de crédito, todavia, não se restringiu à Europa Ocidental. Nas Américas, o Canadá foi o pioneiro na criação de um modelo próprio. Inspirado nos modelos Raiffeissen e Schulze surgiu, em Quebec, o modelo Desjardins, conhecido no Brasil como cooperativas de crédito mútuo, que reunia os sócios sob alguma espécie de vínculo entre eles, destarte "reunindo grupos homogêneos como os de clubes, trabalhadores de uma mesma fábrica, funcionários públicos etc." (PINHEIRO, 2008, p. 24).

Essa confluência de ideários cooperativistas, sobretudo de crédito, e o sucesso que alcançaram onde foram implantadas acabaram por estimular também o surgimento de cooperativas de crédito no Brasil.

Pinheiro (2008, p. 27) assinala como primeira sociedade cooperativa brasileira a "Sociedade Cooperativa Econômica dos Funcionários Públicos de Ouro Preto”, criada em 1889. Contudo, destaca que, anteriormente, existiram outras associações econômicas, a exemplo da Sociedade Beneficente de Juiz de Fora, de 1885, o que dificulta, a seu juízo, a precisão do marco histórico do cooperativismo no Brasil. Por sua vez, Peinado (2006, p. 72) aponta que a primeira cooperativa de crédito brasileira foi fundada em 1902, sob a denominação de Caixa Econômica de Empréstimos 
Amstad, depois denominada de Caixa Rural de Nova Petrópolis, e hoje museu do cooperativismo de crédito brasileiro.

Conforme se observa, o surgimento das cooperativas deu-se na Europa e é datado do século XIX. E embora as cooperativas de crédito não tenham sido as precursoras do movimento cooperativista, elas tiveram origem em razão da necessidade e da demanda de crédito pela população europeia não detentora de capital, a exemplo dos trabalhadores rurais e do proletariado.

Os diversos modelos cooperativistas, sem dúvida, influenciaram para que, no Brasil, se acompanhasse a experiência estrangeira. Tanto que as cooperativas surgiram independentemente do regramento jurídico, pois, somente a partir da Lei no 5.764, de 16 de dezembro de 1971, é que passaram a ter um marco legal adequado às suas especificidades.

\section{VALORES FUNDAMENTAIS DO COOPERATIVISMO}

A adequada compreensão do cooperativismo não se restringe à sua conceituação formal, tornando-se indispensável o acesso às razões e fundamentações sob as quais surgiu e se sustenta.

Conforme demonstrado anteriormente, o cooperativismo teve origem nas necessidades econômicas dos trabalhadores, no contexto do liberalismo econômico europeu clássico, que ampliou as desigualdades sociais de modo a impedir até mesmo o alcance da sobrevivência digna do operariado e do camponês.

Ao invés de aguardarem por uma solução do Estado, as classes trabalhadoras urbanas e rurais, desprovidas de capital e em face da concentração de poder econômico de industriais e detentores de terra, passaram a se associar ou com vistas a garantir melhores condições subjetivas de trabalho ou até de se auto proverem. Se o primeiro fundamento para o associativismo gerou o sindicalismo, o outro propiciou, entre os trabalhadores, a formação do cooperativismo como modelo institucionalizado de unificação de esforços para a produção, consumo, apoio creditício mútuo e outras finalidades.

Contudo, para que a associação com vistas ao crescimento econômico e social se opere, se faz necessária a confluência de valores comuns entre os sujeitos que se dispõem a essa atividade. Valores aqui compreendidos como fatores de orientação da conduta humana, portanto como “variável da mente que faz com que o ser humano decida ou escolha se comportar numa determinada direção e dentro de uma determinada importância" (WEIL, 1994, p. 47). Nesse sentido, o associativismo, do qual o cooperativismo é espécie, sustenta-se sob alguns valores. Inobstante a diversidade de pensadores, e sem deixar de fazer referência a outros valores, Irion (1997) lista como valores mais importantes do associativismo a solidariedade, a liberdade, a justiça social e a equidade, uma vez que fomentam o senso de coletividade na satisfação de interesses e necessidades dos associados, tanto sob o aspecto coletivo quanto individual.

A solidariedade é a premissa básica de auxílio e cooperação mútuos entre dois ou mais 
sujeitos, exigindo-se o rompimento das barreiras do individualismo, para preocupar-se com o outro, de forma a compreender o outro como realidade pessoal, mas também dando reconhecimento à importância social das ações do indivíduo inserido na coletividade. No que tange ao cooperativismo, Rossi (2011, p. 79) assume que este:

[...] pressupõe, para o exercício das atividades que enseja, exatamente essa lógica. A centralização do olhar no "outro", a superação da visão individualista, o esvaziamento do sentido da competição e o realce da noção de ajuda mútua, de operar conjuntamente não só com o outro, mas também por e ao lado dele.

A solidariedade cooperativa representa, portanto, a possibilidade de crescimento econômico coletivo, pois, pelo auxílio creditício mútuo, viabiliza-se a austeridade financeira do associado que dela necessita.

A liberdade, como valor cooperativo, não se revela apenas na possibilidade de ingresso ou saída do associado a qualquer tempo. A liberdade cooperativa também compreende a possibilidade de o associado participar autonomamente das atividades da sociedade, nos limites de seus status jurídico de associado, bem como resguarda a autonomia da cooperativa quanto a seus dirigentes e associados, observando-se, em todos os casos, as regras livremente estatuídas e em conformidade com o Direito.

Por justiça social entende-se que essa "realiza-se pela promoção econômica, educacional e cultural das pessoas por meio da oportunidade de trabalho e de realização pessoal que pode ser implementado pela via cooperativa.” (ROSSI, 2011, p. 80). Neste sentido, o cooperativismo busca dotar de condições os indivíduos para que possam realizar projetos profissionais ou empreender com menores riscos. Percebe-se facilmente esta condição nas cooperativas de trabalho, em que diversos sujeitos fornecem sua força de trabalho para o bem-estar da sociedade cooperativa, não por fim altruísta, mas na perspectiva de fazer prosperar a entidade, cujos resultados serão revertidos aos próprios trabalhadores, condição analogamente observável nas cooperativas de crédito ou consumo, em que há o esforço do associado em prol da cooperativa. Nas cooperativas de crédito a concessão de crédito possibilita a promoção econômica a que se refere Rossi, razão pela qual também detém potencialidade para conduzir à justiça socioeconômica de seus membros.

Sobre equidade e seu significado cooperativo, Irion (1997, p. 50) explica seus três aspectos:

A vertente associativa estabelece deveres e direitos gerais e iguais para todos os sócios especificados nos estatutos, nas decisões das assembleias ou estabelecidos pela administração. A vertente econômica preconiza a participação do associado nos negócios cooperativos e na sustentação da entidade. Chega-se então à distribuição dos resultados econômicos proporcional à participação dos associados nos negócios da cooperativa determinando que a equidade, sob o ponto de vista econômico passa a ser preceituada como "a cada um, segundo sua participação nos negócios cooperativos." A vertente social obriga a cooperativa (dentro de sua capacidade), a assistir os associados de forma equânime, sem qualquer tipo de discriminação, definindo a equidade como "a cada um segundo suas necessidades de assistência." 
Logo, pela equidade se definiria o estabelecimento de direitos e deveres iguais para todos os associados, a distribuição dos resultados proporcional à participação, e a assistência sem discriminação e consonante necessidades.

\section{A CONSTITUIÇÃO E O COOPERATIVISMO}

A Constituição da República Federativa do Brasil, em seu artigo 174, § 2º prevê que "a lei apoiará e estimulará o cooperativismo e outras formas de associativismo.” (BRASIL, 1988). Como será abordado, essa regra constitucional é de fundamental importância no processo de desenvolvimento do país. E há muitos motivos que teriam conduzido o constituinte a positivar esta norma de natureza programática.

Sabe-se, há muito, que o modelo econômico liberal, fundado na livre organização e funcionamento do mercado (nos termos propostos por Adam Smith), é insuficiente para gerar desenvolvimento: produção de riqueza, equidade socioeconômica e proteção ambiental. Partindo dessa premissa é que, desde o início do século XX, considera-se adequada a atuação do Estado para corrigir as distorções oriundas da clássica dinâmica econômica liberal. Desta feita, autorizase o Estado a intervir na economia sempre que se fizer necessário, observando-se, contudo, os direitos e as garantias constitucionais fundamentais dos agentes privados e de padrões específicos de funcionamento da economia capitalista, ainda que com viés social. Por conseguinte, o Estado detém a preferência para atuar de forma indireta na economia, no exercício de suas funções normativa e reguladora (art. 174, caput, da Constituição). Sua atuação direta somente é autorizada por meio de lei e em situações excepcionais, quando necessária aos imperativos de segurança nacional ou sob a premissa de relevante interesse coletivo (artigo 173, caput, da Constituição).

Assim, no modelo econômico constitucionalmente posto, o Estado passa a atuar como agente normativo e regulador e, como tal, detém a legitimidade para definir, nos limites constitucionais, a política econômica nacional. Munido destas prerrogativas, o Estado determina as premissas e diretrizes sobre as quais ele próprio (artigo 173, caput, da Constituição) e os demais agentes econômicos privados devem ou podem atuar.

Ao definir, em seu artigo 174, $\S 2^{\circ}$, que o Estado atuará para estimular o cooperativismo, a Constituição adota um viés dogmático de matriz social-liberal, uma vez que ela impõe um dever econômico-social ao Estado que, na qualidade de agente normativo e regulador da economia, detém o compromisso de viabilizar esse instrumento econômico por meio de regramento infraconstitucional e pela adoção de políticas públicas adequadas à sua efetivação.

Há de se destacar que a norma não restringe o estimulo ao cooperativismo em determinado modelo, mas sim o trata de forma genérica, de modo a abranger diversas de suas modalidades, como crédito, trabalho, consumo, dentre outras, indo, inclusive, mais além, ao assumir que estimulará 
outras formas de associativismo, desde que para fins lícitos e pacíficos (ressalva do artigo $5^{\circ}$, inciso XVII, da Constituição).

O estímulo constitucional ao cooperativismo e ao associativismo recontextualiza a normatividade da Lei ${ }^{\circ}$ 5.764, de 1971, que define a Política Nacional de Cooperativismo, deixando clara a importância deste modelo econômico como estratégia para o desenvolvimento nacional, agora sob a perspectiva da sustentabilidade (produção de riqueza, equidade socioeconômica e proteção ambiental).

Logo, o artigo 174, $\S 2^{\circ}$, da Constituição deve também ser concretizado em consonância com o seu artigo $5^{\circ}$, inciso XXIII, e com todo o rol de normas-princípio previstas no artigo 170 , dentre elas a do dever de estimular ações de proteção ao meio-ambiente na seara da atividade econômica.

Além do direito constitucional ao associativismo (artigo $5^{\circ}$, incisos XVII, XVIII, XIX, XX e XXI, da Constituição), o artigo 5º no inciso XVIII, acrescenta o cooperativismo como direito, assegurando que a criação de cooperativas independe de autorização estatal, desde que respeitadas as formalidades e requisitos previstos em lei, vedando-se ao Estado de interferir em seu funcionamento.

Observe-se, pois, neste aspecto, que o dispositivo constitucional menciona "lei", sendo essa, portanto, ordinária e não complementar, visto que a última, quando necessária, deve ser expressa. Neste ponto, merece questionamento se as resoluções emitidas pelo Banco Central do Brasil seriam instrumentos hábeis na determinação das formas de atuação do cooperativismo de crédito.

Tendo em vista que o Banco Central do Brasil é a agência reguladora responsável pelo funcionamento do Sistema Financeiro Nacional, exercendo o controle do crédito, fiscalização e autorização de funcionamento das instituições financeiras, conforme se depreende do artigo $10^{\circ}$ da Lei $\mathrm{n}^{\circ} 4.595$, de 1964, pode-se concluir que as suas resoluções são válidas ao regularem os parâmetros de funcionamento e a autorização para criação de cooperativas de crédito, pois o termo "lei" resta compreendido como veículo por meio da qual se estabelecem normas (BRASIL, 1964).

A Constituição, ao adotar a premissa de estímulo ao cooperativismo, reconhece a função econômico-democrática da atividade cooperativa (portanto, associativa dos interessados) como mecanismo útil e adequado para também se alcançar o desenvolvimento nacional. Neste sentido, a Constituição adota o cooperativismo como diretriz de planejamento econômico, cujo fim é de "imprimir ao mercado um direcionamento diferente daquele que o regeria se deixado às 'leis naturais"” (FONSECA, 2007, p. 339-340).

Para que o cooperativismo possa funcionar como propulsor de desenvolvimento, se faz necessário que ele se revista de certos valores e características vantajosas que justifiquem a sua importância como elemento de política econômico-social. É nesse sentido que se sustenta, pois, o presente estudo, esclarecendo as razões pelas quais se deve optar pelo cooperativismo de crédito como alternativa de planejamento econômico, constitucionalmente adequado. 


\section{DEFINIÇÃO E NATUREZA JURÍDICA DA COOPERATIVA DE CRÉDITO}

A Lei $n^{\circ} 5.764$, de 1971, fornece, em seu artigo $3^{\circ}$, um conceito de cooperativa nos seguintes termos: "celebram contrato de sociedade cooperativa as pessoas que reciprocamente se obrigam a contribuir com bens ou serviços para o exercício de uma atividade econômica, de proveito comum, sem objetivo de lucro." (BRASIL, 1971).

A partir desse marco legal, Pereira (2006, p. 103) detalha o conceito de cooperativa definindo-a como:

[...] uma associação de pessoas com objetivo profissional nos diversos campos da atividade humana, administrada no modelo da autogestão, operacionalizada por meio de ajuda mútua, destinada à satisfação das necessidades básicas comuns de seus membros. É uma organização de natureza empresarial sem propósito de lucratividade, mediante a qual um grupo de pessoas busca realizar determinados interesses comuns, e tem o capital como instrumento à serviço do homem

Discorrendo, ainda, sobre o conceito de cooperativa a partir de sua finalidade, Mendonça (1954, p. 240) acrescenta que elas são:

Institutos modernos, tendentes a melhorar as condições das classes sociais, especialmente dos pequenos capitalistas e operários. Elas procuram libertar essas classes da dependência das grandes indústrias por meio da união das forças econômicas de cada uma; suprimem aparentemente o intermediário, nesse sentido: as operações ou serviços que constituem o seu objeto são realizados ou prestados aos próprios sócios e é exatamente para esse fim que se organiza a empresa cooperativada.

Diversos conceitos sobre cooperativas podem ser apresentados, contudo, há de se destacar a essência deste tipo societário. A sociedade cooperativa se revela na reunião de esforços individuais com o fito de obter benefício comum, contando, para tanto, com a colaboração conjunta de seus associados. Para isso, a cooperativa se constitui por intermédio de contrato social, do qual a pessoalidade dos associados é elemento característico, bem como a não intencionalidade lucrativa da sociedade, já que seus resultados serão compartilhados necessariamente pelos associados. Portanto, pode-se afirmar que, no que tange à classificação das cooperativas, sua tipologia resultará da especificidade da sua atividade societária, conforme se depreende das lições de Mizabel Derzi (1988), que assenta na abertura dos tipos, mais maleáveis que os conceitos, essencialmente fechados e estáticos.

Não é objetivo deste estudo discorrer, em minúcias, sobre as características das cooperativas. Contudo, os conceitos legal e doutrinário apresentados revelam as principais especificidades do cooperativismo, quais sejam, o não interesse lucrativo da entidade (muito embora possa haver o interesse lucrativo dos associados) e o fato de ser a cooperativa uma sociedade simples, conforme 
disposição do artigo 982 do Código Civil (BRASIL, 2002). Todavia, insta apenas apresentar quais seriam as características basilares das cooperativas listados no artigo $4^{\circ}$ da Lei 5.764, de 1971:

Art. $4^{\circ}$ As cooperativas são sociedades de pessoas, com forma e natureza jurídica próprias, de natureza civil, não sujeitas a falência, constituídas para prestar serviços aos associados, distinguindo-se das demais sociedades pelas seguintes características:

I - adesão voluntária, com número ilimitado de associados, salvo impossibilidade técnica de prestação de serviços;

II - variabilidade do capital social representado por quotas-partes;

III - limitação do número de quotas-partes do capital para cada associado, facultado, porém, o estabelecimento de critérios de proporcionalidade, se assim for mais adequado para o cumprimento dos objetivos sociais;

IV - incessibilidade das quotas-partes do capital a terceiros, estranhos à sociedade;

$\mathrm{V}$ - singularidade de voto, podendo as cooperativas centrais, federações e confederações de cooperativas, com exceção das que exerçam atividade de crédito, optar pelo critério da proporcionalidade;

VI - quórum para o funcionamento e deliberação da Assembleia Geral baseado no número de associados e não no capital;

VII - retorno das sobras líquidas do exercício, proporcionalmente às operações realizadas pelo associado, salvo deliberação em contrário da Assembleia Geral;

VIII - indivisibilidade dos fundos de Reserva e de Assistência Técnica Educacional e Social;

IX - neutralidade política e indiscriminação religiosa, racial e social;

$\mathrm{X}$ - prestação de assistência aos associados, e, quando previsto nos estatutos, aos empregados da cooperativa;

XI - área de admissão de associados limitada às possibilidades de reunião, controle, operações e prestação de serviços (BRASIL, 1971).

Ao optar pelo regramento das cooperativas como sociedades simples, o Código Civil, não expõe tal motivação, não aclarando sua distinção em relação às sociedades empresárias, já que em seu artigo 966 não determina a lucratividade como elemento essencial das sociedades empresárias, limitando-se a assentar que "considera-se empresário aquele que exerce profissionalmente atividade econômica organizada para a produção ou circulação de mercadorias ou serviços."

Observa-se que do artigo supramencionado não há qualquer ressalva para que as cooperativas não sejam consideradas como sociedades empresárias, todavia por expressa disposição legal do artigo 982, parágrafo único, do mesmo diploma legal, deve-se considerar como simples a sociedade cooperativa.

Apesar de se divergir de tal conceituação, notadamente pela falta de motivação expressa no Código Civil, Krueger tenta justificar as cooperativas como sociedades simples; a esse respeito, o autor assevera que: 
de distinguir essa da empresária: o sócio necessariamente opera com a sociedade; não há possibilidade de existir um sócio exclusivamente detentor de capital, e nesta única condição exercer a condição de mando sobre a sociedade e que a sua participação nos resultados operacionais possa se resumir à distribuição de lucros. A sociedade empresária é aquela em que não somente existe essa possibilidade, como a estrutura organizacional é erigida em torno dessa possibilidade (KRUEGER, 2006, p. 83).

É razoável o argumento levantado, todavia acaba sendo forçosa a hermenêutica, uma vez que a lei não evidenciou as motivações que impedem as cooperativas de serem consideradas sociedades empresárias. Todavia, por expressa disposição do artigo 982, parágrafo único, do Código Civil, deve-se classificar as cooperativas como sociedades simples, que, segundo Krueguer, teriam como distinção marcante a inexistência de intento lucrativo pela sociedade.

No que concerne aos tipos de cooperativas, a Lei nº 5.764, de 1971, trata apenas de expressar as formas que as cooperativas podem assumir, quais sejam: singulares, centrais (ou federações) e confederações. As primeiras são destinadas à prestação direta de serviços aos associados, ao passo que as centrais seriam constituídas por três ou mais singulares e teriam por objetivo orientar, integrar e facilitar as atividades e a utilização recíproca dos serviços. As confederações, por sua vez, seriam formadas pela reunião de três ou mais centrais, da mesma ou de diferentes modalidades de cooperativas, orientando e coordenando as atividades das filiadas, em defesa, portanto, do interesse global do sistema cooperativo, conforme se depreende dos artigos 6 a 9 da referida lei.

O artigo 10, caput, da Lei $\mathrm{n}^{\circ} 5.764$, de 1971, estabelece que as cooperativas também se classificam de acordo com a natureza ou objeto da atividade desenvolvida. Neste sentido, diversas modalidades de cooperativas podem ser encontradas. Vasconcelos (2001, p. 22-27) exemplifica, num rol extensivo, diversos tipos de cooperativas, como: de produção agrícola ou industrial, de trabalho, de beneficiamento de produtos, de compras em comum, de consumo, de abastecimento, de crédito, de seguro, de construção de casas populares, de editoras e de cultura intelectual, escolares e mistas. Além dessas, acrescentam-se ainda as cooperativas de transporte, de catadores lixo, dentre tantas outras possíveis. Contudo, este trabalho foca-se nas cooperativas de crédito.

Classificando-se as cooperativas conforme a atividade a que se dedicam, as sociedades cooperativas de crédito são aquelas que têm o objetivo de concessão de crédito aos seus associados, ou, nas palavras de Salomão Neto $(2014$, p. 72) "são entidades que têm por objeto a cooperação mútua entre seus associados através da economia sistemática e do uso adequado do crédito." Por conseguinte, as sociedades cooperativas de crédito funcionam como players do mercado financeiro, vez que a atividade de concessão creditícia é tipicamente financeira, compreendida entre "coleta, intermediação ou aplicação de recursos financeiros próprios ou de terceiros, em moeda nacional ou estrangeira”, consonante prevê o artigo 17 da Lei n ${ }^{\circ}$ 4.595, de 1964, ao definir as atividades típicas de instituições financeiras.

Atualmente, a extensão dos serviços prestados por essas cooperativas tem sido ampliada para além da mera concessão creditícia. Neste sentido, a Resolução nº 4.434, de 2015, do Banco Central do Brasil, as autoriza a prestar as seguintes atividades: 
Art. 17. A cooperativa de crédito pode realizar as seguintes operações e atividades, além de outras estabelecidas na regulamentação em vigor:

I - captar, exclusivamente de associados, recursos e depósitos sem emissão de certificado;

II - obter empréstimos e repasses de instituições financeiras nacionais ou estrangeiras, inclusive por meio de depósitos interfinanceiros;

III - receber recursos oriundos de fundos oficiais e, em caráter eventual, recursos isentos de remuneração ou a taxas favorecidas, de qualquer entidade, na forma de doações, empréstimos ou repasses;

IV - conceder créditos e prestar garantias, somente a associados, inclusive em operações realizadas ao amparo da regulamentação do crédito rural em favor de associados produtores rurais;

$\mathrm{V}$ - aplicar recursos no mercado financeiro, inclusive em depósitos à vista $\mathrm{e}$ depósitos interfinanceiros, observadas as restrições legais e regulamentares específicas de cada aplicação;

VI - proceder à contratação de serviços com o objetivo de viabilizar a compensação de cheques e as transferências de recursos no sistema financeiro, de prover necessidades de funcionamento da instituição ou de complementar os serviços prestados pela cooperativa aos associados;

VII - prestar, no caso de cooperativa central de crédito e de confederação de centrais:

a) a cooperativas filiadas ou não, serviços de caráter técnico, inclusive os referentes às atribuições tratadas no Capítulo VIII;

b) a cooperativas filiadas, serviço de administração de recursos de terceiros, na realização de aplicações por conta e ordem da cooperativa titular dos recursos, observadas a legislação e as normas aplicáveis a essa atividade; e

c) a cooperativas filiadas, serviço de aplicação centralizada de recursos, subordinado a política própria, aprovada pelo conselho de administração, contendo diretrizes relativas à captação, aplicação e remuneração dos recursos transferidos pelas filiadas, observada, na remuneração, proporcionalidade em relação à participação de cada filiada no montante total aplicado; e

VIII - prestar os seguintes serviços, visando ao atendimento a associados e a não associados:

a) cobrança, custódia e serviços de recebimentos e pagamentos por conta de terceiros a pessoas físicas e entidades de qualquer natureza, inclusive as pertencentes aos poderes públicos das esferas federal, estadual e municipal e respectivas autarquias e empresas;

b) correspondente no País, nos termos da regulamentação em vigor;

c) colocação de produtos e serviços oferecidos por bancos cooperativos, inclusive os relativos a operações de câmbio, bem como por demais entidades controladas por instituições integrantes do sistema cooperativo a que pertença, em nome e por conta da entidade contratante, observada a regulamentação específica;

d) distribuição de recursos de financiamento do crédito rural e outros sujeitos a legislação ou regulamentação específicas, ou envolvendo equalização de taxas de juros pelo Tesouro Nacional, compreendendo formalização, concessão e liquidação de operações de crédito celebradas com os tomadores finais dos recursos, em operações realizadas em nome e por conta da instituição contratante; e

e) distribuição de cotas de fundos de investimento administrados por instituições autorizadas, observada a regulamentação aplicável editada pela Comissão de Valores Mobiliários (CVM) (BANCO CENTRAL DO BRASIL, 2015). 
Desta ampla gama de atividades, percebe-se que atualmente as cooperativas de crédito em muito se assemelham aos bancos em razão dos serviços por elas prestados. Todavia, há que se destacar as diferenças entre estas instituições financeiras, inclusive as vantagens de cada uma delas.

\section{DISTINÇÕES ENTRE COOPERATIVAS DE CRÉDITO E BANCOS COMERCIAIS}

O artigo 17 da Lei $n^{\circ}$ 4.595, de 1964, traz o conceito de instituição financeira, nos seguintes termos:

Art. 17. Consideram-se instituições financeiras, para os efeitos da legislação em vigor, as pessoas jurídicas públicas ou privadas, que tenham como atividade principal ou acessória a coleta, intermediação ou aplicação de recursos financeiros próprios ou de terceiros, em moeda nacional ou estrangeira, e a custódia de valor de propriedade de terceiros (BRASIL, 1964).

Porém, Salomão Neto (2014, p. 17) adverte da demasiada amplitude que o mencionado artigo confere às instituições financeiras, de tal forma que se interpretado em literalidade poucas atividades e empresas nacionais escapariam ao enquadramento como instituições financeiras. Assim, coube à doutrina especificar e aclarar o que seria considerado instituição financeira para fins legais. Lamy Filho e Pedreira (1992, p. 479) argumentam que "o traço característico das chamadas instituições financeiras é a captação de recursos do público em geral para investimentos financeiros, cujos resultados são atribuídos aos respectivos subscritores".

Nesse contexto, e por força de sua própria natureza, as cooperativas de crédito são tidas por instituições financeiras, o que se reconhece no artigo 25 da Lei no 4.594, de 1964, ao determinar que "as instituições financeiras privadas, exceto as cooperativas de crédito, constituir-se-ão unicamente sob a forma de sociedade anônima”. Consequentemente, e apesar da sua forma social constitutiva, as cooperativas de crédito classificam-se como instituição financeira. Todavia, não há de se confundi-las com bancos comerciais, pois as cooperativas de credito:

[...] são organizações que têm por escopo desenvolver a chamada mutualidade. No setor creditício, sua finalidade consiste em propiciar empréstimo a juros módicos a seus associados, estando subordinadas, na parte normativa, ao Conselho Monetário Nacional e, na parte executiva, ao Banco Central. (ABRÃO, 2016, p. 66).

Destarte, assume-se do mutualismo a principal distinção entre cooperativas de crédito e bancos comerciais, cujo interesse é tipicamente privado, portanto, lucrativo.

Apesar de cooperativas de crédito e bancos serem agentes financeiros, há diferenças 
fundamentais entre ambos os modelos que, por consequência, podem levar os interessados a optarem por um ou outro modelo. Para fins didáticos de melhor vislumbre das distinções entre esses agentes, nos utilizaremos do quadro elaborado por Meinen e Port (2014).

Quadro 1 - Titulo

\begin{tabular}{|c|c|}
\hline Bancos & Cooperativas de crédito \\
\hline$\alpha)$ São sociedades de capital & a) São sociedades de pessoas \\
\hline $\begin{array}{l}\text { ß)O poder é exercido na proporção do número } \\
\text { de ações }\end{array}$ & $\begin{array}{l}\text { b) O voto tem poder igual para todos (uma } \\
\text { pessoa, um voto) }\end{array}$ \\
\hline 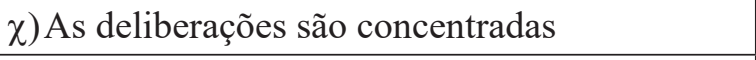 & c) As decisões são partilhadas entre muitos \\
\hline $\begin{array}{l}\text { ס) Os administradores são terceiros (homens de } \\
\text { mercado) }\end{array}$ & $\begin{array}{l}\text { d) Os administradores são do meio } \\
\text { (associados) }\end{array}$ \\
\hline ع) $\mathrm{O}$ usuário das operações é mero cliente & e) O usuário é o próprio dono (cooperado) \\
\hline $\begin{array}{l}\text { ф)O usuário não exerce qualquer influência na } \\
\text { definição dos produtos e na sua precificação }\end{array}$ & $\begin{array}{l}\text { f) Toda política operacional é decidida } \\
\text { pelos próprios usuários/donos }\end{array}$ \\
\hline ү) Podem tratar distintamente cada usuário & $\begin{array}{l}\text { g) Não podem distingui: o que vale para } \\
\text { um vale para todos (art. } 37 \text { da Lei n. } \\
5.764 / 71 \text { ) }\end{array}$ \\
\hline $\begin{array}{l}\text { १)Preferem o público de maior renda e maiores } \\
\text { corporações }\end{array}$ & $\begin{array}{l}\text { h) Não discriminam, servindo a todos os } \\
\text { públicos }\end{array}$ \\
\hline $\begin{array}{l}\text { 1) Priorizam os grandes centros (embora não } \\
\text { tenham limitação geográfica) }\end{array}$ & $\begin{array}{l}\text { i) Não restringem, tendo forte atuação nas } \\
\text { comunidades remotas }\end{array}$ \\
\hline 甲)Têm propósitos mercantis & $\begin{array}{l}\text { j) A mercancia não é cogitada (art. } 79, \\
\text { parágrafo único, da Lei n }{ }^{\circ} 5.764 / 71 \text { ) }\end{array}$ \\
\hline $\begin{array}{l}\text { ๙) A remuneração das operações e dos serviços } \\
\text { não tem parâmetro/limite }\end{array}$ & $\begin{array}{l}\text { k) O preço das operações e dos serviços } \\
\text { tem como referência os custos e } \\
\text { como parâmetro as necessidades de } \\
\text { reinvestimento }\end{array}$ \\
\hline $\begin{array}{l}\text { 7) Atendem em massa, priorizando, ademais, o } \\
\text { autosserviço }\end{array}$ & $\begin{array}{l}\text { 1) O relacionamento é personalizado/ } \\
\text { individual, com o apoio da informática }\end{array}$ \\
\hline $\begin{array}{l}\text { M)Não têm vínculo com a comunidade e o } \\
\text { público-alvo }\end{array}$ & $\begin{array}{l}\text { m) Estão comprometidas com as } \\
\text { comunidades e os usuários }\end{array}$ \\
\hline v) Avançam pela competição & n) Desenvolvem-se pela cooperação \\
\hline o) Visam o lucro por excelência & $\begin{array}{l}\text { o) O lucro está fora do seu objeto, seja pela } \\
\text { sua natureza, seja por determinação } \\
\left.\text { legal (art. } 3^{\circ} \text { da Lei no } 5.764 / 71\right)\end{array}$ \\
\hline 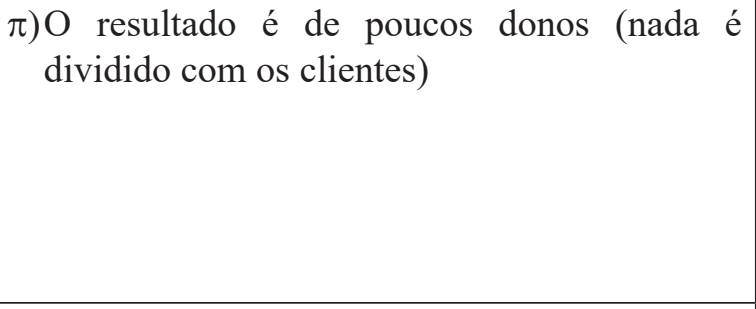 & $\begin{array}{l}\text { p) O excedente (sobra) é dividido entre } \\
\text { todos (usuários), na proporção de } \\
\text { suas operações individuais, reduzindo } \\
\text { ainda mais o preço final pago pelos } \\
\text { cooperados e aumentado a remuneração } \\
\text { de seus investimentos }\end{array}$ \\
\hline $\begin{array}{l}\text { 日) No plano societário são regidos pela lei das } \\
\text { Sociedades Anônimas }\end{array}$ & $\begin{array}{l}\text { q) São reguladas pela Lei Cooperativista e } \\
\text { por legislação própria }\end{array}$ \\
\hline
\end{tabular}

Fonte: Meinen e Port (2012, p. 51). 
Em que pese não ser objetivo do presente estudo discorrer de forma pormenorizada sobre as diversas distinções entre estes agentes financeiros, cumpre destacar algumas delas, por se considerar fundamentais para a sua compreensão.

A primeira das distinções a ser anotada é quanto à natureza jurídica dos bancos e das cooperativas de crédito, visto que os primeiros são sociedades de capital, enquanto estas são sociedades de pessoas. A diferenciação, neste aspecto, é sobre a importância dos atributos pessoais para a constituição da sociedade, uma vez que na sociedade de pessoas (no caso das cooperativas) eles [os atributos] são condições sine qua non para que se forme a sociedade, que se assenta sob a affectio societatis, correspondente à intenção das partes de contratarem reciprocamente com base na pessoa com quem se firma o contrato e de seus atributos pessoais. Já na sociedade de capital atributos pessoais como "as aptidões, a personalidade e o caráter dos sócios são irrelevantes, para o sucesso ou insucesso da empresa explorada pela sociedade." (COELHO, 2014, p. 42).

Outro aspecto distintivo importante é quanto ao "peso" do voto, posto que nas sociedades cooperativas cada associado tem um voto, diferentemente do que ocorre nos bancos, em que o voto tem "peso" diferente, proporcionalmente ao número de ações de cada acionista. No cooperativismo tem-se, portanto, como efeito benéfico, a redução da disputa dos conflitos pelo poder de controle societário, inobstante não seja capaz de extingui-los. Tal aspecto impede, ainda, a criação de tratamento diferenciado entre os cooperados, de tal sorte que o que valer para um valerá para todos, como se observa, por exemplo, no artigo 37 da Lei no 5.764 , de 1971:

Art. 37. A cooperativa assegurará a igualdade de direitos dos associados sendolhe defeso:

I - remunerar a quem agencie novos associados;

II - cobrar prêmios ou ágio pela entrada de novos associados ainda a título de compensação das reservas;

III - estabelecer restrições de qualquer espécie ao livre exercício dos direitos sociais (BRASIL, 1971).

Ademais, há uma diferença fundamental na relação entre os associados e a cooperativa. Contrariamente ao que ocorre com os bancos, os associados não são simples clientes da cooperativa, mas, simultaneamente, sócios e destinatário dos serviços. Destarte, todos os cooperados estão aptos a participar das decisões de direção e na operacionalidade da própria cooperativa, podendo decidir, até mesmo, sobre a precificação dos serviços

Distinção relevante também é o não interesse lucrativo das sociedades cooperativas, o que Pontes de Miranda justifica na medida em que o fundamento do cooperativismo reside na superação das adversidades do capitalismo. Para o autor,

[...] há que ser respeitada a prevalência mutualística. Daí ter-se de refutar qualquer teoria ou opinião doutrinária que considere a mesma causa das sociedades cooperativas e a causa das sociedades lucrativas, que são tipicamente capitalistas. Mais se coopera, naquelas, para evitar o fim lucrativo de terceiros que para 
lucrar. O fato de haver capital não pode ser base para se afirmar que há propósito capitalístico. Por vezes o capital da sociedade é para lutar contra atos alheios capitalísticos (MIRANDA, 1965, p.431-432).

O intuito das sociedades cooperativas é o de viabilizar condições para que os comerciantes de menor porte possam atuar e concorrer com as grandes empresas capitalistas em um cenário econômico menos desiquilibrado. A não intencionalidade de lucro reflete esse ideal. Os associados não estariam reunidos para lucrar individualmente, mas sim para angariarem para si melhores condições econômicas que lhes permitam a superação das adversidades e injustiças existentes em ambiente concorrencial desigual e acirrado.

O eventual resultado financeiro positivo, conhecido por "sobras", não é, pois, o fim da cooperativa, mas, corresponde ao excedente do aporte investido pelos associados e que não foi utilizado, razão pela qual deve ser devolvido aos cooperados na mesma proporção de seus investimentos, em padrões estabelecidos pela própria cooperativa, como acentua a Resolução $n^{\text {o }}$ 4.434, de 2015, do Banco Central do Brasil. Ademais, a eventual existência de sobras não é elemento essencial e nem caracterizador das cooperativas.

O cooperativismo de crédito traz, ainda, a vantagem de fomentar o desenvolvimento economicamente do grupo de cooperados, bem como da região em que se insere. Nesse sentido, basta atentar que os rendimentos das cooperativas, bem como os empréstimos aos associados, propiciam capital aos próprios cooperados. Esse capital, por sua vez, pode vir a retornar, como crescimento econômico, para os negócios dos cooperados (caso seja uma cooperativa de empresários) ou para o cotidiano da localidade, já que o ganho de capital aumenta a renda dos associados e, consequentemente, seu poder de compra e até de produção, o que faz movimentar a economia da região. Além disso, as cooperativas podem proporcionar um retorno intangível para os associados, na medida em que propiciam encontros entre os cooperados, o que, per si, já é potencialmente desenvolvedor de novos negócios.

Interessante ressaltar que nos próprios ideais cooperativistas está a responsabilidade social das cooperativas, que buscam não somente o desenvolvimento do cooperativismo como modelo econômico, mas também revelam o intuito educativo e emancipador dos próprios cooperados, visto que os ganhos e investimentos no sistema cooperativo propiciam retornos positivos para a coletividade.

\section{CONCLUSÃO}

A opção constitucional pelo estímulo ao cooperativismo é reflexo de um processo histórico, que remete à matriz de desenvolvimento do Estado liberal. O movimento cooperativo surge como forma de superação das adversidades oriundas do capitalismo, que se revelou, em sua dinâmica clássica, prejudicial à sociedade. Ao longo do século XIX, trabalhadores urbanos e rurais não usufruíam dos benefícios daquele modelo socioeconômico, posto que a renda se concentrava em pequena parcela social, detentora dos meios de produção. 
O cooperativismo surgiu no continente europeu e, rapidamente, expandiu-se como alternativa econômica voltada para o desenvolvimento. Apesar de ter sido inaugurado como meio para promover maior poder de consumo aos associados, a cooperação com vistas à concessão creditícia a taxas de juros e encargos menores que aqueles cobrados pelos detentores de capital logo se revelou bastante viável para os pequenos produtores e trabalhadores urbanos e rurais necessitados de crédito. Em pouco tempo, o cooperativismo de crédito teve alta expressão nos diversos Estados do continente europeu, apresentando pequenas distinções formais entre os modelos espontaneamente instituídos.

O estímulo ao cooperativismo de crédito relaciona-se à importância da atividade financeira como elemento propulsor de desenvolvimento, o que o torna objeto de intervenção estatal. Contudo há várias espécies de instituições financeiras, sendo os bancos e as cooperativas de crédito as mais comumente encontradas no âmbito privado. Todavia, há diferenças fundamentais entre ambas que podem influenciar a escolha dos cidadãos e das pessoas jurídicas interessadas na obtenção de crédito.

Contudo, o Estado, na qualidade de agente fomentador de políticas públicas, tem, no cooperativismo de crédito, um modelo social e economicamente atrativo para promover crescimento econômico com equidade socioeconômica.

Dentre as vantagens apresentadas pelo cooperativismo de crédito destacam-se: a) a condição simultânea de sócio e cliente das sociedades cooperativas, visto que os próprios usuários do serviço podem participar do processo decisório, inclusive não havendo distinção quanto ao peso de seus votos, que independem da quantidade de capital do associado; b) a pessoalidade em relação a quem se contrata, sendo elemento valorativo nas sociedades cooperativas, de forma que interessam-lhes os atributos pessoais dos sócios, o que é interessante quando considerado o interesse de ajuda e auxílio mútuos dos próprios associados; c) o interesse não lucrativo das sociedades cooperativas, o que resulta na redução da remuneração dos serviços por ela prestados em comparação com os bancos comerciais, o que beneficia toda a economia, uma vez que a concorrência leva à redução dos preços; d) a concessão creditícia por intermédio do sistema de cooperação permite que o destinatário se utilize do crédito mais vantajosamente concedido para reaplicá-lo em seu empreendimento econômico ou para a quitação de suas dívidas perante outros credores, o que propicia a circulação de riquezas pelo menor custo e incentivo à produção e ao consumo.

A conjunção dessas vantagens, notadamente o menor custo dos serviços e a possibilidade de participação no processo decisório, influenciam na opção do interessado por tornar-se associado às cooperativas de crédito, o que induz o crescimento do sistema cooperativo. Porém, a mera demanda pelo cooperativismo não é suficiente para a sua adequada utilização como elemento de viabilização do desenvolvimento socioeconômico, fazendo-se necessária a adoção de políticas públicas que o estimulem. 
Há de se destacar, ainda, como razões para o estímulo ao cooperativismo, os valores sobre os quais ele se sustenta. Valores como: a) a solidariedade que se revela no auxílio mútuo entre os cooperados e entre estes e a sociedade, o que torna a concorrência não depredatória; b) a liberdade de empreendedorismo existente entre as atividades dos associados em relação à cooperativa; c) o senso de equidade entre os associados e entre estes e a sociedade, dados os diversos programas sociais e de capacitação que podem ser promovidos no contexto da atividade cooperada. $\mathrm{O}$ reconhecimento desses valores leva à mudança da percepção individual e coletiva em relação à economia e, a longo prazo, permite criar bases ideológicas para o desenvolvimento na conjugação de seus três pilares: geração de riqueza pelo empreendedorismo inovador, equidade socioeconômica e proteção e preservação ambiental.

A constatação do aumento numérico do sistema cooperativo mesmo num cenário de recessão econômica demonstra sua aptidão para a promoção de crescimento socioeconômico. Ademais, o modelo de cooperativismo de crédito auxilia os associados em crise, pois lhes propicia fonte de crédito, sujeita à fiscalização do Banco Central do Brasil, o que representa garantia ao não colapso do sistema.

Ressalta-se, também, a peculiaridade de que o crédito concedido é utilizado na própria região, de sorte que a circulação de riqueza local e regional aumenta, o que representa efeito benéfico para o desenvolvimento econômico territorialmente descentralizado. Logo, o cooperativismo de crédito detém alta potencialidade para atuar na redução de desigualdades socioeconômicas no contexto federativo, mantendo, assim, plena sintonia com o sistema constitucional vigente.

Destarte, entende-se que o cooperativismo de crédito compreende interessante proposta de desenvolvimento sócio-econômico para os associados e até mesmo de desenvolvimento regional, uma vez que fomenta a circulação de riquezas.

Deste modo, consta-se que a hipótese apresentada como resposta ao tema-problema foi verificada ao longo do trabalho. O sucesso que o cooperativismo de crédito encontrou em diversos Estados, aliado aos valores que o norteiam e às vantagens subjetivas e coletivas que ele propicia, são instrumentos hábeis para propiciar que o Estado implemente políticas públicas para fomentálo de modo adequado e eficiente e de maneira a concretizar o princípio normativo-programático do artigo 174, $\S 2^{\circ}$, da Constituição da República Federativa do Brasil, ou seja, de estímulo ao cooperativismo, notadamente em seu vertente de crédito.

\section{REFERÊNCIAS}

ABRÃO, Nelson. Direito bancário. 16. ed. São Paulo: Saraiva, 2016.

BANCO CENTRAL DO BRASIL. Resolução $n^{\circ}$ 4.434, de 5 de agosto de 2015. Dispõe sobre a constituição, a autorização para funcionamento, o funcionamento, as alterações estatutárias e o cancelamento de autorização para funcionamento das cooperativas de crédito 
e dá outras providências. Disponível em: <https://www.bcb.gov.br/pre/normativos/busca/ downloadNormativo.asp?arquivo=/Lists/Normativos/Attachments/48507/Res_4434_v1_O.pdf $>$. Acesso em:

BRASIL. [Constituição (1988)]. Constituição da República Federativa do Brasil. Disponível em: <http://www.planalto.gov.br/ccivil_03/Constituicao/Constituicao.htm>. Acesso em:

BRASIL. Lei $n^{o}$ 10.406, de 10 de janeiro de 2002. Institui o Código Civil. Disponível em: http:// www.planalto.gov.br/ccivIl_03/Leis/2002/L10406.htm>. Acesso em:

BRASIL. Lei $n^{\circ}$ 4.595, de 31 de dezembro de 1964. Dispõe sobre a Política e as Instituições Monetárias, Bancárias e Creditícias, Cria o Conselho Monetário Nacional e dá outras providências. Disponível em: < http://www.planalto.gov.br/ccivil_03/LEIS/L4595.htm>. Acesso em:

BRASIL. Lei $n^{\circ}$ 5.764, de 16 de dezembro de 1971. Define a Política Nacional de Cooperativismo, institui o regime jurídico das sociedades cooperativas, e dá outras providências. Disponível em: <http://www.planalto.gov.br/ccivil 03/LEIS/L5764.htm>. Acesso em:

COELHO, Fábio Ulhoa. Curso de direito comercial. São Paulo: Saraiva, 2014. v. 2.

COURI, Sérgio. Liberalismo e societalismo. Brasília: Unb, 2001.

DERZI, Mizabel de Abreu Machado. Tipo ou conceito no direito tributário? Belo Horizonte: Universidade Federal de Minas Gerais, 1988.

FONSECA, João Bosco Leopoldino da. Direito econômico. 5. ed. Rio de Janeiro: Forense, 2007. IRION, José Eduardo Oliveira. Cooperativismo e economia social. São Paulo: STS, 1997.

KOSLOVSKI, João Paulo. A evolução histórica das cooperativas de crédito. In: GRUPENMACHER, Betina Treiger (Coord.). Cooperativas e tributação. Curitiba: Juruá, 2001. p. 19-32.

KRUEGER, Guilherme. As cooperativas como sociedades simples. In: KRUEGUER, Guilmerme (Org.). Cooperativismo e o novo código civil. 2. ed. Belo Horizonte: Mandamentos, 2006. p. 90-105.

LAMY FILHO, Alfredo; PEDREIRA, José Luiz Bulhões. A Lei das S/As. Rio de Janeiro: Renovar, 1992.

MEINEN, Ênio; PORT Márcio. Cooperativismo financeiro, percurso histórico, perspectivas e desafios. Brasília Editora Confebras, 2014.

MENDONÇA, José Xavier Carvalho de. Tratado de direito comercial brasileiro. Rio de Janeiro: Freitas Bastos, 1954.

MIRANDA, Pontes de. Tratado de direito privado. Rio de Janeiro: Borsoi, 1965. Tomo XLIX.

MORENO, Maria de Jesús Egido. Cooperativas de crédito em la comunidad autônoma del País Vasco e Navarra: retos e futuros. San Sebastian: Universidad del País Vasco: Instituto del 
Derecho Cooperativo y Economía Social, 1999.

OLIVEIRA, Alexandre Miranda. A evolução do cooperativismo de crédito no Brasil e na Europa: algumas considerações para o seu fortalecimento. In: LEITE, Jacqueline Rosadine de Freitas; SENRA, Ricardo Belízio de Faria (Org.). Aspectos jurídicos das cooperativas de crédito. Belo Horizonte: Mandamentos, 2005. p. 21-53.

OLIVEIRA, Márcio Luís de. A constituição juridicamente adequada. 2. ed. Belo Horizonte: D’Plácido, 2016.

PEINADO, Lineu Bonora. Cooperativas de Crédito. In: ALMEIDA, Marcus Elidius Michelli; BRAGA, Ricardo Peake. Cooperativas à luz do código civil. São Paulo: Quartier Latin, 2006. p. 71-93.

PEREIRA, João Batista Brista. Cooperativas, uma alternativa. In: ALMEIDA, Marcus Elidius Michelli; BRAGA, Ricardo Peake. Cooperativas à luz do código civil. São Paulo: Quartier Latin, 2006. p. 97-131.

PINHEIRO, Marcos Antônio Henriques. Cooperativas de crédito: história da evolução normativa no Brasil. 6. ed. Brasília: BCB, 2008.

PRADO, Flávio Augusto Dumont. Tributação das cooperativas à luz do direito cooperativo. Curitiba: Juruá, 2011.

ROSSI, Amélia do Carmo Sampaio. Cooperativismo à luz dos princípios constitucionais. Curitiba: Juruá, 2011.

SALOMÃO NETO, Eduardo. Direito bancário. 2. ed. São Paulo: Atlas, 2014.

SINGER, Paul. Introdução à economia solidária. São Paulo: Editora Fundação Perseu Abramo, 2002.

VASCONCELOS, Francisco das Chagas. Cooperativas: coletânea de doutrina, legislação, jurisprudência e prática. São Paulo: Iglu, 2001.

WEIL, Pierre. A nova ética. Rio de Janeiro: Rosa dos Tempos, 1994.

Como citar: FRADE, Eduardo Silveira; OLIVEIRA, Márcio Luís. Cooperativismo de crédito: uma alternativa de desenvolvimento socioeconômico. Revista do Direito Público, Londrina, v. 13, n. 3, p. 153-174, dez. 2018. DOI: 10.5433/24157-108104-1.2018v13n3 p 153. ISSN: 1980$511 X$.

Recebido em: 04/07/2018

Aprovado em: 07/11/2018 